\title{
Several Thoughts on TV Advertising Music
}

\author{
Hui Lu \\ School Music of Cai Jikun, Minjiang University, Fuzhou, 350001, China
}

Keywords: TV advertising, music, role, thoughts

\begin{abstract}
As the basic element of TV advertising, music is very common in TV advertising and plays a very important role. This paper mainly explains the role of TV music, analyzes problems in its development, and puts forward several thoughts.

With the continuous development of domestic economy, TV industry develops increasingly quickly, and promotes TV advertising to be widely popularized and strongly comprehensive integrated with various factors including art, culture, entertainment, business and science \& technology etc. Today, TV advertising covers every corner of people's life, and TV advertising music, as a special publicity method of TV advertising, has been increasingly concerned by advertisers.
\end{abstract}

\section{Overview of TV advertising and TV advertising music}

TV advertising attracts people's attention by intuitive pictures and verbal language mainly by relying on various artistic forms and ways of expression combined with rich colors and lively features, and is an advertising form that is increasingly concerned by advertisers. TV advertising is also an art with unique artistic characteristics, and is a very important creative element in TV, and conveys product information to the audience through TV communication. TV advertising music expresses strongly theme emotions of advertising, creates unique advertising atmosphere, and shapes product brand image, to deepen visual effects of the audience and thus promote sales of products in advertising. Apply proper music to TV advertising to give play to its orientation and arouse consumers' desire to buy.

Along with today's increasingly prosperous TV advertising industry, requirement for TV advertising music gets increasingly high. Original folk songs and rap are quite unitary, and today's music tends to be diversified. Besides, there are increasingly more music styles, such as national music, classical music, pop and rock etc. In addition, with continuous scientific and technological progress, there are diverse instruments, such as national instruments, western instruments and subsequent electronic musical instruments, all of which bring stronger emotional appeal and expressive force for TV advertising music.

\section{Analysis of the role of music in TV advertising}

Firstly, in TV advertising, music has been playing an increasingly important role, and is one of very prominent component. Product publicity by using music in TV advertising could enable the audience to get different product information interpretation ways, promote product brands to be more emotional, and make the audience establish feelings for products. By combining music with images in TV advertising organically, TV advertising pictures could have stronger emotional appeal and show product images very well to the audience. Compared with text, music has better memorizing effects, affects emotions of the audience unknowingly, and thus leads them to the atmosphere of TV advertising, and communicates with them through nice melody, note and rhythm etc. If applied to certain TV advertising, music would be a proprietary mark of products.

Secondly, creativity of TV advertising could be expressed more smoothly through good music. Therefore, enterprises should choose music which complements with pictures in TV advertising to build special emotional atmosphere for products. For example, background of advertising picture of Chivas is Alaska surrounded by ice and snow, while a group of friends are fishing. Background music of this advertising expresses quietness, pleasure and freedom away from busy cities, and 
people in the picture are immersed in the music melody enjoying indulging and arbitrariness, generating great influence on the audience in cities under prolonged heavy burden and making them cannot help having a spiritual journey. In this advertising, mere picture background and spokesmen could not express such artistic conception at all, and mere background music could not express theme of this advertising either. Therefore, both should be combined to get optimal effects.

Thirdly, good music of TV advertising can better help the audience remember the advertising. Compared with pictures, sound, especially music created after constant perfection, can touch people's emotions easier and have very good spiritual communication with the audience. Nowadays, many families will do other things while broadcasting TV advertising, and they would not even watch the screen, but would focus on TV advertising music. Therefore, TV advertising music plays a very important role in this process and even acts as advertising. So, TV advertising music should be unified with product brand. Music has strong permeability, and could play better communication effects than visual language while popular, and could complement with visual language in terms of communication effects.

Fourthly, music and TV advertising could publicize each other. TV advertising with good music could be accepted and favored by the audience, while good music could also become popular through TV advertising. Some enterprises hire very popular singers to speak for their products, and combine music with TV advertising, so that consumers who love celebrities and concern about advertising of these singers would know product brands in TV advertising.

\section{Analysis of problems in TV advertising music}

Firstly, creators of TV advertising music haven't done systematic strategic planning of brand individuality, have fuzzy brand core value, and lack good guidance, so that TV advertising music cannot achieve expected effects and even produce negative influence on product brand because of wrong selection of music. Creators also ignore brand individuality, lack innovation and even imitate other brands.

Secondly, advertisers rely on celebrities to speak for their products. However, if they fail to choose those in line with product specifications, adverse effects may be resulted. Under improper application of celebrity effects, although consumers can still be attracted to products in advertising to a certain degree and cognition and popularity are enhanced, consumers would be confused about difference among products. For example, Korean celebrity Kim Hee Seon speaks for TCL mobile phones, but her temperament is inconsistent with product images. Besides, she is mainly concerned by middle school students and college students, but target consumers of TCL are white-collar workers, and thus she could not represent the brand images and result in more losses than gains.

Thirdly, TV advertising music mainly includes national music, current popular music or Chinese and foreign famous songs etc, resulting in problems in music copyright. Therefore, infringement would be caused, although background music of TV advertising could attract audience because of its popularity and cognition and lower costs than original music, spread in a wide range, arouse resonance of audience, and facilitate market expansion of advertisers through brands. TV advertising uses popular music or Chinese and foreign famous songs. If advertisers do not get consent of composers of such music, meet needs of advertising works blindly and do not notice legal issues related to intellectual property, there would be increasingly serious infringement. Relevant laws provide that permission of copyright owners shall be obtained first before using their works and pay corresponding remuneration; otherwise, infringement would be constituted. For example, Shanghai GoldenHorse Advertising Company and Only Company use Really Miss You by Yang Xiangyue and Li Hanying as background music of advertising of Only Meizhizhi Capsule, and are accused of infringement.

Fourthly, theme of TV advertising should be perfectly combined with TV advertising music, coordinate and supplement each other, in order to give full play to expected effects of TV advertising; otherwise, effects of the entire TV advertising would be affected. However, some advertisers simply focus on economic interests and neglect social interests. Moreover, some advertising lacks creativity and leads to aesthetic fatigue of the audience. In addition, some false 
advertising also occurs in TV advertising, bringing great influence on the development of domestic TV advertising industry. Advertisers' low-taste and vulgar TV advertising would result in pollution and shoddy of social morality. For instance, TV advertising of Airwaves gum brings negative influence to adolescents, and has low quality, and thus looks too flippant compared with conservative traditional thoughts.

\section{Thoughts on TV advertising music and countermeasures}

Firstly, TV advertising music creators should attach great importance to fineness of creation, pursue quality music constantly and apply to TV advertising, in order to make TV advertising music perfect. By unifying advertising brand individuality and TV advertising music, classical TV advertising music would be created. If music is inconsistent with themes of TV advertising, it should not be applied as background music; otherwise, it would affect effects of brand information communication and audience's receiving ways of product information. Therefore, enterprises shall attach importance to TV advertising music, select background music that is consistent with advertising themes and does not violate individualized features of product brands, combine advertising pictures with background music effectively, and enhance product publicity effects. In addition, TV advertising music shall be associated with advertising, or the audience can hardly understand the music. In this case, even if this TV advertising music is widespread, it could not bring benefits with its function and has low fineness. Thus, during creation of TV advertising music, extract organically associated elements between music and advertising, make perfection more perfect, and achieve maximum benefits of TV advertising music.

Secondly, TV advertising music shall make full use of traditional Chinese elements, discover cultural connotation, and promote continuous development of TV advertising industry. However, it should be noted that application of traditional Chinese culture in TV advertising doesn't necessarily bring successful TV advertising. Therefore, traditional elements shall be processed artistically, to avoid negative factors in TV advertising and rejection of the audience. During TV advertising production, enterprises show local customs and practices and concepts of places where target markets are located by making rational use of traditional culture, in order to attract attention of the audience and affect their emotions. Besides, they should also attach enough importance to modern cultural concepts, and try to have novel innovation of TV advertising and music, and produce quality advertising that attracts people's attention, in order to improve market shares.

Thirdly, creation of TV advertising music should fit with advertising brand features. For example, elegant and primitive music is mainly suitable for high-end luxury, while common popular music applies for popular consumer goods. This is ignored by many enterprises when creating TV advertising music.

Fourthly, intention of advertising planning shall be expressed accurately, in order to express advertising goals and themes perfectly. Advertising theme is mainly formed by organically integrating three factors, namely advertising goal, information individuality and consumer psychology etc. TV advertising music shall keep up with advertising goals, if not, expected sound effects of TV advertising music would not be reached, and thus conflicts may be formed between visual and auditory information of TV advertising, information confusion of the audience may be led to, and affect the audience's correct judgment of information.

Fifthly, enterprises shall grasp psychology and mentality of the audience accurately, and then create effective TV advertising music based on psychological and mental characteristics of the audience. Advertising is mainly about information exchange between enterprises and product users in order to publicize enterprises, goods and services etc. None of advertising is created for all people, but has respective target markets, while TV advertising music is for this part of people. When TV advertising music serves for TV advertising, and arouses emotional resonance of this part of audience, so that they would concern about brand image shaped jointly by this advertising and TV advertising music and meet their pursuit of artistic perception. On the contrary, TV advertising couldn't achieve good effects, if the audience rejects TV advertising and music can't be understood or understood accurately, i.e. intention of advertising planning is not met. 
Sixthly, enterprises shall not imitate or use product advertising of competitors. The audience generally has favorable impression of enterprise products that enter the market first. Adverse effects would be generated if enterprises ignore this and use background music of competitors in their own TV advertising, as the audience would reject such product brands or even they advertise for competitors. Therefore, by doing this, enterprises could not enhance their products and may even damage their own brand images. To carry out TV advertising, enterprises shall use music with distinct individuality and melody and lyrics in line with product individuality, and thus improve product sales and profits.

Seventhly, enterprises shall achieve echo between TV music and advertising voiceover in terms of rhythm structure of TV advertising. Advertising voiceover can help the audience think of dynamic TV music, and promote effects of the entire TV advertising music to be close to inner feelings of the audience, so that the audience may accept this TV advertising music and even this advertising and products. Good TV advertising music involves many factors. Music created for TV advertising should not be complex and difficult to understand, as the audience would easily have deep impression of TV advertising if they could sing after having listened for several times. It should be noted that music that enterprises use should comply with local cultural environment to avoid cultural conflicts etc.

\section{Conclusions}

Along with continuous progress of network era and increasing development of electronic media, new visual and auditory technologies constantly occur, and are gradually applied to advertising media. Today, media characteristics develop gradually to be integrated, and advanced mobile media with visual and auditory functions constantly emerge, providing a very good development platform for TV advertising music. Along with the development of sound advertising communication, visual advertising bears great pressure in this era. Therefore, TV advertising music has very good development prospect, and if applied appropriately, it is conducive to enterprise brand building and thus enterprises could gain ideal economic interests.

\section{References:}

[1] Li Min. On TV Advertising Music [D]. East China Normal University, 2008 (11): 125 126.

[2] Song Yu. Study on TV Advertising Music [J]. Northern Music, 2014 (3): 137 138.

[3] Zhao Yunxin. On the Application and Role of Music in TV Advertising [J]. Art and Literature for the Masses, 2011 (5): 143 144. 